\title{
A institucionalidade da assistência social na proteção social brasileira
}

The institutionality of the social assistance in the brazilian social protection

\section{Fabricio Fontes de Andrade*}

\begin{abstract}
Resumo:
Este artigo busca sistematizar a configuração da assistência social enquanto política pública no que toca o sistema brasileiro de proteção social. Para tanto, analisa-se a dinâmica do Sistema Único de Assistência Social - SUAS, seus avanços e retrocessos, apontando a institucionalidade do SUAS, com as possíveis tensões e inovações institucionais apontadas a partir de sua configuração jurídico-política. Assim, visualiza-se a trajetória de consolidação da Assistência Social perpassada de avanços e tensões, inovações e conservadorismos, que se expressam nas diversas dinâmicas que perpassam a consolidação do SUAS.
\end{abstract}

Palavras-Chave: Assistência social. Proteção social. SUAS.

\begin{abstract}
:
This article attempts to systematize the configuration of social assistance as a public policy regarding the Brazilian system of social protection. To this end we analyze the dynamics of the Unified Social Assistance - SUAS, its advances and setbacks, pointing to the institutional SUAS, with the possible tensions and institutional innovations pointed from his legal and political setting. Thus, we can see the path of consolidation of Social Assistance and tensions permeated by advances, innovations and conservatism, which are expressed in various dynamics that underlie the consolidation of SUAS.
\end{abstract}

Keywords: Social assistance. Social protection. SUAS.

\section{Introdução}

É objetivo deste artigo demarcar a dinâmica da Assistência Social enquanto política pública no âmbito da proteção social brasileira. As questões que se colocam na construção deste artigo fundamentalmente são: Quais as grandes inovações da

\footnotetext{
* Professor Assistente I da Universidade Federal do Recôncavo da Bahia - UFRB. Mestre em Desenvolvimento Social pela Universidade Estadual de Montes Claros - Unimontes. Ganhador do Prêmio Roani Cunha de Desenvolvimento Social 2010.fabriciof8@yahoo.com.br
} 
assistência social no Brasil no período pós-constitucional, especialmente as inovações do Sistema Único de Assistência Social - SUAS?; Não obstante, quais as principais tensões na implementação deste sistema em relação ao âmbito dos direitos sociais?

Assim, busca-se enfocar as inovações e retrocessos da assistência social no Brasil, não a partir de si mesma, mas situando-a nos marcos dos limites impostos na conjuntura de uma política econômica e das correlações de forças políticas presentes nas disputas no seio da sociedade, buscando superar tanto as visões fatalistas quanto conformistas em relação aos processos e relações sociais.

O enfoque se desenvolverá em três momentos: Primeiramente farei um breve resgate da formação do padrão brasileiro de proteção social, tendo em vista seus principais elementos e mudanças. Posteriormente buscar-se-á delinear a especificidade da trajetória da Assistência Social no Brasil, seus principais marcos recentes como a Constituição Federal de 1988 e a Lei Orgânica da Assistência Social; em um terceiro momento realizar-se-á uma análise sobre o SUAS, as possíveis inovações e tensões em torno do seu conteúdo.

\section{Proteção social no Brasil: um breve resgate}

Antes de empreendermos a análise da proteção social na sociedade brasileira se faz necessária a caracterização do que entendemos ser o Sistema Brasileiro de Proteção Social, que durante o passar dos anos foi se modificando. Neste sentido, caracteriza-se que:

[...] entende-se por Sistema Brasileiro de Proteção Social o conjunto de políticas e programas governamentais destinado à prestação de bens e serviços e à transferência de renda, com o objetivo de cobertura dos riscos sociais, garantia dos direitos sociais, equalização de oportunidades e enfrentamento das condições de destituição e pobreza (CARDOSO JUNIOR; JACCOUD, 2005, p. 194).

O Sistema de Proteção Social Brasileiro em suas diversas matizes setoriais tem mesmo que insuficientemente consolidado - caracterizado algum nível de institucionalização fundamentalmente após a Constituição de 1988. 
Neste âmbito, o Sistema Único de Assistência Social (SUAS), atua na organização de um Sistema de Proteção Social não contributiva, mas marcadamente perpassado pela focalização e seletividade, opera o acesso aos benefícios e serviços pela via da necessidade não pela via do pertencimento e da cidadania social.

Desde o surgimento das medidas públicas de proteção social no Brasil, estas são marcadas pela estratificação do acesso a serviços e do público alvo. Dessa forma, historicamente, o atendimento das demandas se restringe ao lócus ocupacional no qual determinado trabalhador está incluído, assim sendo, vivencia-se neste âmbito, um sistema de proteção social de benefícios duais, uma vez que grande parte da população, trabalhadores autônomos desempregados- não obtinha acesso aos serviços e benefícios no sistema de proteção público, estas camadas ficavam relegadas a ações de caráter filantrópico e religioso. O cerne da política social corporativa está no individualismo, concentrando transferências individuais, posteriores a contribuições (ex-post), não existe assim, qualquer motivação coletivista, altruísta, de equidade ou de justiça social (FONSECA, 2001).

Tendo em vista as especificidades descritas acima, configura-se a combinação perversa entre paternalismo e medidas repressivas no trato da "questão social", em que as oligarquias colocavam em seu favor o funcionamento das instituições e da burocracia estatal. No enfoque de tal dinâmica, entre os estudos brasileiros de construção de um perfil periférico de proteção social, é marcante o estudo clássico de Santos (1979), que versa sobre a configuração e eficácia das políticas sociais brasileiras. Para Santos (1979), o conceito central para se entender a política social brasileira seria o de cidadania regulada ${ }^{1}$.

O conceito de cidadania regulada alinha o sistema de proteção social brasileiro com regime Conservador/Corporativo proposto por Esping-Andersen, em que o Status de cidadão está ligado à inserção no mercado formal de trabalho. Portanto, as políticas sociais empreendidas no Brasil tinham preponderantemente um corte operário-

\footnotetext{
1 “Por cidadania regulada entendo o conceito de cidadania cujas raízes encontram-se, não em um código de valores políticos, mas em um sistema de estratificação ocupacional, e que, ademais, tal sistema de estratificação ocupacional é definido por norma legal. Em outras palavras são cidadãos todos aqueles membros da comunidade que se encontram localizados em qualquer uma das ocupações reconhecidas e definidas em lei" (SANTOS, 1979, p. 75).
} 
industrial, baseadas na seleção dos beneficiários por caráter corporativo, complementadas com a ação de famílias e grupos na proteção social aos indivíduos.

Tais situações reforçam a estratificação social, baseando o acesso aos direitos sociais a uma questão de mérito, ou seja, a mediação e extensão dos direitos se sistematizavam de acordo com a capacidade de inserção laborativa do beneficiário, portanto, de acordo com seu mérito no mercado de trabalho.

A inserção das classes trabalhadoras na cena política brasileira se fez via o estabelecimento e intervenção controlada de uma burocracia clientelista, que se complexificou sob o um viés excludente a elitista, ou seja, resultando na ampliação das burocracias estatais e o impedimento da formação de identidades coletivas.

As mudanças empreendidas no período militar caracterizaram-se pelo seu caráter tecnocrático e autoritário, que visava à regulação dos conflitos sociais tendo em vista a segurança nacional. De acordo com Raichelis (2000) durante este período aumentou-se muito a cobertura das medidas sociais, incorporando grupos até então excluídos do sistema de proteção.

Embora neste contexto tenha ocorrido a expansão dos direitos sociais, - em contradição com a restrição dos direitos civis e políticos - tal expansão é caracterizada como excludente, pois, não operou efeitos redistributivos e deixou à margem de sua expansão segmentos pauperizados da população. Neste momento aprofunda-se a reestruturação das políticas sociais no Brasil em busca da superação das características populistas persistentes desde a década de 1930, em busca de um aparelho estatal centralizado objetivando o aumento da racionalidade técnica do mesmo. Destaca-se que neste período caracteriza-se a subsunção dos interesses sociais aos interesses econômicos, relegando as decisões ao privatismo da burocracia.

No entanto, esta ampliação da proteção social se dava sob o ponto de vista da legitimação social do regime militar, se fez especialmente junto às camadas médias e aos assalariados urbanos pela propaganda massiva acerca do sucesso do milagre brasileiro, criando condições de sustentação social e política para o relacionamento com os diversos segmentos sociais. Sob tal dinâmica, as demandas sociais eram atendidas em um mix de intervenções que transitavam na dualidade assistência/repressão. 
Tal condição das políticas sociais acarretou que a implementação institucional e desenvolvimento das políticas sociais no Brasil - desde as primeiras medidas até a década de 1980 - mostrava, sobretudo, uma baixa capacidade de superação da desigualdade social e um descompasso entre crescimento econômico e desenvolvimento social. Analisando historicamente, constata-se que na década de 1980 , as políticas sociais brasileiras se caracterizavam pela centralização decisória e financeira na esfera federal, relegando aos municípios a execução de programas sob as determinações de comando federal, comprometendo a eficiência dessas políticas (BERETTA; MARTINS, 2004).

A partir da década de 1970 inicia-se a superação deste padrão, juntamente com a luta pela redemocratização do país. As lutas pela redemocratização do país integram uma agenda de reformas institucionais em busca de maior efetividade e eficiência das políticas e dos programas, supondo um reordenamento das políticas para responder às demandas sociais em quadro de regressividade das condições sociais. Tais mudanças engendradas no processo de redemocratização resultaram na ampliação das medidas sociais garantidas a registradas no texto constitucional.

Embora o estudo de Santos (1979) conceitue a proteção social brasileira desta forma, as mudanças empreendidas pela constituição de 1988 trazem novas mediações políticas na intervenção social. Deste modo, é possível afirmar que temos um sistema de proteção amplo, indubitavelmente por vezes incompleto, inconsistente e ineficaz, mas, com a presença de características consolidadas no que diz respeito às instituições, recursos humanos e definição de fontes orçamentárias previstas constitucionalmente. Nesse contexto, ao caracterizar o sistema de proteção após as mudanças constitucionais, Pereira (2006a) denomina o modelo brasileiro como Misto, uma vez que apresenta características dos diversos regimes propostos por Esping-Andersen (1991), quais sejam:

Intervenções públicas tópicas e seletivas - próprias dos regimes liberais -; adoção de medidas autoritárias e desmobilizadoras dos conflitos sociais - típicas dos modelos conservadores - e, ainda, o estabelecimento de esquemas universais e não contributivos de distribuição de benefícios e serviços - característicos dos regimes socialdemocratas. (PEREIRA, 2006a, p. 127).

Portanto as mudanças ressaltadas na Constituição de 1998 estabeleceram na Seguridade Social brasileira a Previdência, Saúde e Assistência Social. Ao se comparar as 
modalidades de intervenção destas políticas com a análise proposta por Pereira (2006a), constata-se que a Saúde compõe o sistema universal com a implantação do Sistema Único de Saúde (SUS), o caráter Corporativo é advindo da Previdência Social (embora tenha incorporado segmentos não contributivos), que predominantemente pressupõe contribuição prévia, já a Assistência Social è historicamente marcada pelos excessivos testes de meio e o estigma atribuído aos usuários dos serviços, típicos dos regimes liberais.

As mudanças institucionais ocorridas nos direitos sociais introduzem um aprofundamento do caráter redistributivo das políticas e da responsabilidade pública na oferta e coordenação dos benefícios e serviços. Traz importantes mudanças no direcionamento das medidas sociais, buscando ampliar o acesso, assim como romper, com o caráter contributivo da lógica do seguro social. Engendra-se uma visão mais ampliada da proteção social ancorada na concepção da seguridade social, com o conseqüente comprometimento do Estado e da sociedade em financiar o sistema através de impostos específicos, e não somente a contribuição individual.

Em direção às prerrogativas estabelecidas na Constituição Federal de 1988, na revisão do pacto federativo, o sistema de proteção social brasileiro passou por um redesenho, com o objetivo de transferir paulatinamente competências, funções, responsabilidades, bem como recursos dos demais entes federados para as esferas municipais de governo.

No bojo destas transformações institucionais e operacionais, inicia-se o processo de municipalização das políticas sociais, sendo transferidas aos municípios responsabilidades, não só na área orçamentária e fiscal, mas no campo do planejamento e da gestão das políticas sociais, que para sua efetivação requerem estratégias de intervenção e incentivo para a superação das insuficiências técnicas locais. A descentralização, enquanto gestão municipal, supõe que "municipalização significa uma articulação de forças do município como um todo para a prestação dos serviços, cujos coresponsáveis seriam a prefeitura municipal e organizações da sociedade civil". (STEIN, 1997, p. 89).

Porém, é necessário demarcar uma virada conservadora, pois, no mesmo instante da afirmação dos direitos sociais elencados na Constituição Federal de 1988, articula-se 
no país um bloco de viés conservador que busca a partir da vitória eleitoral, escamotear o conteúdo progressista da constituição. Ou seja, efetivaram-se neste país manobras para o descumprimento dos preceitos constitucionais e a descaracterização das propostas, bem como a restrição fiscal dos gastos sociais.

Neste sentido, se torna importante na análise da política de assistência social em nível municipal, o entendimento das características gerais dos sistemas de proteção social, a fim de se dar conta do caminho que esta sendo traçado pelo SUAS em sua implementação nos municípios, estabelecendo em que sentido se direciona a universalidade proposta no marco legal da LOAS e da Constituição de 1988, bem como se busca estabelecer as reais mediações que impedem a universalização da cobertura, impondo obstáculos e direcionamentos via focalização.

\section{A trajetória da política de assistência social no Brasil.}

Historicamente, a política de Assistência Social se configurou no Brasil de maneira marginal aos direitos sociais, esteve ligada a atividade voluntarista carregada por uma forte carga moralista de patrimonialismo, clientelismo e das diversas expressões da cultura do favor. No Estado Novo criou-se a LBA (Legião Brasileira de Assistência) que tinha o objetivo de cuidar e dar assistência às famílias dos pracinhas que foram a II Guerra Mundial. Embora tenha sido o primeiro aparato estatal de intervenção social na Assistência Social, a LBA tradicionalmente se constituiu como um lugar de arranjos clientelísticos e da filantropia estatal. (RAICHELIS, 2000).

Em sua gênese a LBA era composta por um grupo elitista de mulheres, que se destinava ao apoio familiar junto às famílias dos soldados que foram chamados a combater na II Guerra Mundial. Ou seja, "[...] a LBA assim compôs seu patrimônio, definindo seus programas em torno da necessidade de substituir o antigo espírito filantrópico e religioso da assistência social por formas de atendimento fundadas no conhecimento técnico-científico" (SPOSATI; FALCÃO; TEIXEIRA, 1995, p. 63)

Concomitantemente a tais processos, temos o surgimento da profissionalização do Serviço Social, buscando efetuar o controle sobre as pessoas, sob a influência de Igreja Católica e de caráter elitista, trazendo valores de ajuda ao próximo e da filantropia. Segundo dissertam Carvalho e lamamoto (1985), este foi o imaginário social em que se 
afirmou a consolidação da Assistência Social influenciada pela Doutrina Social Católica. Neste contexto, funda-se a visão de que a miséria e a pobreza eram decorrentes da má formação social das coletividades - sobretudo a classe operária - em que, estes poderiam colocar em risco a boa sociedade e gerar fissuras sociais, prejudiciais à manutenção da paz e da coesão ${ }^{2}$.

Neste escopo, a assistência social se restringiu a situações específicas e inerentes ao ciclo de vida do ser humano. Embora sempre tratada no debate político, - as ações da assistência no combate a pobreza- estas eram mediadas como intervenção em um espectro específico que escapou à lógica inexorável da ação civilizadora da modernização no Brasil. Diante disto decorre a baixa representatividade da Assistência Social no campo das políticas sociais:

A identidade da assistência social é definida pelo negativo, por ser a ação que os outros setores não desejam implementar, é a populaçãoalvo que os outros setores não entendem como de sua competência. $E$ esse sinal negativo de sua identidade tem repercussão imediata no fato de o setor da assistência jamais ser reconhecido como um interlocutor válido no conjunto dos setores que compõem a política social, mesmo porque jamais conseguiu se constituir em política de assistência social, mas tão somente numa somatória de programas desarticulados (COHN; DRAIBE; KARSCH, 1995, p. 8).

Situações com estas acarretam a estreiteza da concepção da assistência social, em que se entende tal conteúdo como apenas um processo solidário, fragilizando sua especificidade no quadro das políticas sociais e metamorfoseando cidadania em relações de troca e favor.

Soma-se a estes aspectos o assistencialismo, que muitas vezes no discurso dos mais variados atores sociais é abordado de forma simplista. O conceito de assistencialismo não se situa em um campo a - histórico, mas inserido nas situações demarcadas por características que se diferem no que diz a sua condição espaço-tempo.

\footnotetext{
${ }^{2}$ No que toca a emersão do Serviço Social enquanto profissão, inserida na divisão sócio-técnica do trabalho, entende-se que "O Serviço Social se gesta e se desenvolve como profissão reconhecida na divisão social do trabalho, tendo por pano de fundo o desenvolvimento capitalista industrial e a expansão urbana, processos esses aqui apreendidos sob o ângulo das novas classes sociais emergentes e das modificações verificadas na composição dos grupos e frações de classes que compartilham o poder do Estado em conjunturas históricas específicas" (CARVALHO; IAMAMOTO, 1985, p. 77).
} 
Deste modo, Alayon (1995) disserta que "o assistencialismo é uma das atividades sociais que historicamente as classes dominantes implementaram para reduzir minimamente a miséria que geram e para perpetuar o sistema de exploração." (ALAYON, 1995, p. 48) Na efetivação destas mediações assistencialistas, estabelecidas em tempos históricos diferenciados, corroboraram os mais diversos atores públicos e privados, filantropos e religiosos, que intencionalmente estabeleciam as conexões das práticas assistencialistas nas suas situações concretas.

Não obstante, a Assistência Social carrega consigo o legado histórico da imprevisibilidade das ações, relegadas à boa vontade do solidarismo, quando não ligados à chamada individualização da questão social ${ }^{3}$ de que nos fala Castel (1998). Na sociedade brasileira, este quadro regressivo de política pública alçou muros de grande magnitude em direção à não estruturação da Assistência Social afiançadora do direito social.

A inscrição da prática assistencialista na assistência social brasileira se deu atravessada de focalismo, reducionismo, identificada com os desprovidos, despossuídos de capacidade econômica e "moral", que para ser reconhecido enquanto atendido pela política de assistência social, tinha que se mostrar pobre dentre os mais pobres. Deste modo, visualiza-se uma estreita relação entre assistência social e o conceito de pobreza. Pobreza que é marcada pelas suas múltiplas dimensões e faces, que se expressam cotidianamente na vida das pessoas, ou seja, as dimensões da pobreza superam a vinculação unívoca entre falta de renda e condição de pobreza. Assim, ao se enfocar a assistência social enquanto mediadora da pobreza absoluta (meramente vinculada à renda) desqualifica-se o conteúdo e especificidade desta política.

A exposição de tal quadro leva ao que Sposati, Falcão e Teixeira (1995) conceituam como Cidadania Invertida, ou seja, para ter acesso aos direitos e aos serviços sociais o possível beneficiário deve mostrar-se um não-cidadão, que não tem acesso aos demais direitos. Neste sentido, as mediações estabelecidas pelas ações da Assistência Social se caracterizavam pela dinâmica da triagem, das classificações, das demarcações dos necessitados, não das necessidades.

\footnotetext{
3 "Sem a mediação dos direitos coletivos, a individualização das ajudas [...] correm sempre o risco de encontrar a velha lógica da filantropia: jure fidelidade e será socorrido". (CASTEL, 1998, p. 607).
} 
Esses processos que são, via de regra, conformados pela formação do Estado e a institucionalização do pensamento liberal no Brasil, que, ao contrário do contexto europeu, surge não para superar a lógica do feudalismo e da monarquia, mas, filtrado pelas elites nacionais consolida uma estrutura de privilégios e de privatização da esfera pública. Tais condições conformaram práticas sociais arraigadas e perpassadas pela tensão entre a originalidade e o conservadorismo das provisões sociais.

No bojo das transformações ocorridas na sociedade brasileira na década de 1980 no período de democratização do Brasil - possibilitou-se que a Política de Assistência Social alcançasse viabilidade de estruturar-se enquanto Política Social no campo da Seguridade Social brasileira, consagrada no texto constitucional de 1988.

No âmbito das discussões sobre as mudanças institucionais no escopo das políticas sociais brasileiras, chega-se ao diagnóstico de um descompasso na capacidade das políticas sociais se realizarem enquanto medidas eficazes e eficientes na redução das desigualdades e combate a pobreza, ou mesmo da efetivação de processos de desenvolvimento social. $\mathrm{Na}$ avaliação de tais processos entende-se que tomou corpo na agenda social brasileira uma agenda reformista buscando ampliar os princípios sociais do sistema brasileiro de proteção social precedente à Constituição Federal.

Portanto, vislumbrar e efetivar a Assistência Social enquanto direito de Proteção Social requer a redefinição e a superação dos padrões subalternos em que se assentaram historicamente as práticas ligadas a esta política, tais como a benemerência, caridade e sua ação individualizada.

\section{Mudanças institucionais da assistência social e sua trajetória no marco da CF} 1988.

Salienta-se que embora a Constituição Federal de $1988^{4}$ tenha elevado a Política de Assistência Social ao caráter de política pública, sua concretização não aconteceu (ou está

\footnotetext{
${ }^{4}$ A CF88 é um marco histórico "ao ampliar legalmente a proteção social para além da vinculação com o emprego formal. Trata-se de uma mudança qualitativa na concepção de proteção que vigorou no país até então, pois inseriu no marco jurídico da cidadania os princípios da seguridade social e da garantia de direitos mínimos e vitais à reprodução social. Nesse sentido, houve uma verdadeira transformação quanto ao status das políticas sociais relativamente e suas condições pretéritas de funcionamento. Em primeiro lugar, as novas regras constitucionais romperam com a necessidade do vínculo empregatício/contributivo na estruturação e concessão de benefícios previdenciários aos trabalhadores oriundos do mundo rural.
} 
acontecendo) em "mar de calmaria". É fato que os diferentes governos federais resistiram veementemente em investir na configuração da Assistência Social no campo das políticas sociais de Estado.

Destaca-se neste contexto acima explicitado, a luta pela regulamentação do artigo 203 da Constituição Federal de 1988, realizado na LOAS (lei 8742 de 1993). Assim sendo, a LOAS traz consigo uma gama de acúmulos advindos da luta histórica pela afirmação de um novo padrão de Assistência Social no Brasil, sendo que nestes termos, "A LOAS é um documento juspolitico [...] que expressa no seu conteúdo aparentemente neutro toda a gama de discussões que caracterizaram a história da Assistência Social" (PEREIRA, 1998, p. 69-70). O artigo 10 da LOAS, seguindo os princípios constitucionais, define a assistência social como direito do cidadão garantido através de dever do Estado, como política de proteção social não contributiva.

Compartilhando com Sposati (2001), referencia-se a idéia de que a Assistência Social enquanto partícipe do sistema de proteção social brasileiro deve ser uma "política com conteúdo próprio voltado para a provisão [...] da universalização dos mínimos sociais como padrões básicos de inclusão" (SPOSATI, 2001, p. 62).

Embora o arcabouço jurídico legal estabelecido pela Constituição Federal de 1988, e pela aprovação da LOAS em 1993, tenha corroborado para o avanço do aspecto jurídico formal da política de Assistência Social, estas (a CF e a LOAS) apresentam importantes debilidades, sobretudo, por fatiar o público-alvo de sua intervenção (crianças, velhos, mulheres etc.) e por rebaixar a linha de pobreza brasileira ao status de indigência, escamoteando os reais objetivos de uma política que deve se pautar por seu caráter desmercadorizante e a busca pela universalidade no acesso aos direitos e serviços sociais.

Não obstante, nota-se que as ações no âmbito da assistência social acabam se restringindo a grupos sociais específicos e, sobretudo, condicionados ao nível de renda, em que o acesso a serviços e benefícios é operacionalizado pela focalização e seletividade

\footnotetext{
Em segundo lugar, transformaram o conjunto de ações assistencialistas do passado em um embrião para a construção de uma política de assistência social amplamente inclusiva. Em terceiro, estabeleceram o marco institucional inicial para a construção de uma estratégia de universalização no que se refere às políticas de saúde e à educação básica. Além disso, ao propor novas e mais amplas fontes de financiamento - alteração esta consagrada na criação do Orçamento da Seguridade Social - estabeleceu condições materiais objetivas para a efetivação e preservação dos novos direitos de cidadania inscritos na idéia de seguridade e na prática da universalização" (IPEA, 2006, p.8)
} 
através dos testes de meios. Tal situação demarca a não cobertura de significativos contingentes populacionais, que invariavelmente dependem de ações individuais e particulares para a garantia da sobrevivência.

Porém, a implementação da LOAS não aconteceu de forma linear, uma vez que enfrentou grandes resistências dos governantes, sobretudo no período do governo FHC $(1995-2002)^{5}$. As medidas neoliberais adotadas por este governo escamotearam a possibilidade de estruturação de um sistema de proteção social público no Brasil, em detrimento de uma medida truculenta de adoção do Programa Comunidade Solidária. A lógica do programa acarretou uma fragilidade da possibilidade de implementação dos padrões de gestão estabelecidos na LOAS.

De acordo com Souza (2006), as estratégias preconizadas pelo Programa Comunidade Solidária o afirmaram enquanto um programa que "inspirado no princípio da solidariedade e da subsidiariedade, reiterou a assistência social como dever moral, e não como um direito de cidadania, conquistado por meio de um movimento de luta por uma sociedade democrática" (SOUZA, 2006, p. 26).

Sob a égide do pensamento neoliberal, as ações do Programa Comunidade Solidária caminharam em sentido oposto ao preconizado nos parâmetros estabelecidos pela LOAS para a estruturação de um sistema de proteção social, atribuindo à responsabilidade estatal caráter marginal no controle, oferta a administração de serviços e programas sociais dirigidos a coletividade.

Em decorrência das estratégias neoliberais ensejadas no Programa Comunidade Solidária, em contra-tendência ao que está proposto e pensado na Constituição Federal de 1988, a municipalização ao invés de consolidar um novo pacto federativo, estabelecendo novas formas de pactuação entre os entes federados, acarretou o deslocamento das responsabilidades entre as diversas instâncias de governo, indefinição de competências e orçamentos, precariedade no sistema público de oferta de serviços e a pujança de iniciativas de caráter privado e filantrópico na proteção social.

Os fundamentos das políticas sociais característicos dos movimentos de ajuste econômico neoliberal apresentam principalmente: a Focalização, a Privatização. A

\footnotetext{
${ }^{5}$ Neste sentido, de acordo com Cardoso Junior e Jaccoud (2005) a média do gasto social federal com medidas de assistência social no período de 1995-2002 gira em torno de 2,4\% do orçamento total. Vê-se portanto, o baixo nível de incremento orçamentário no referido período.
} 
focalização se justifica no cerne das idéias neoliberais pela necessidade de se redirecionar os investimentos sociais concentrando-os, sobretudo nos mais pobres, acarretando segundo Draibe (1993) uma nova forma de beneficência e benemerência no âmbito do Estado, que seleciona os pobres dentre os mais pobres. A privatização por sua vez é fundamentada em um entendimento de melhor racionalidade no uso dos recursos, configurando o que Bóron (1995) denomina "satanização do Estado" e santificação do mercado na oferta dos bens e serviços.

No âmbito da assistência social emergem um escopo de novos atores: as empresas "socialmente responsáveis"; ONGs; que fundamentam o que Yazbeck (2000) denomina "refilantropização" da questão social. A focalização e a retirada do Estado enquanto instância que possui primazia na oferta de serviços e benefícios de caráter universal - de acordo com o preconizado na LOAS - provoca importantes restrições dos direitos sociais e da cidadania.

Sob a égide de tal visão acima explicitada, impõe-se a compreensão da Assistência Social como "[...] Um ato subjetivo de motivação moral, movido espontaneamente pela boa vontade e pelo sentimento pena, comiseração [...]" (PEREIRA, 2007, p. 218). Ao recorrer-se a inconsistência de tal análise, a assistência social se torna uma categoria antitética das categorias analíticas que conferem sistematicidade aos modernos sistemas de proteção social, tornando-se, pois, um anti-direito que estigmatiza e humilha quem dele necessita.

Ao analisar os aspectos concernentes à implantação da política de Assistência Social no ano de 2003, Sposati (2006) elenca algumas características que emperraram a estruturação de um sistema republicano de proteção social, dentre as características destacam-se sinteticamente algumas:

- Inadequada relação convenial

- Homogeneização no trato dos municípios

- Precarização do caráter democrático

- Caráter estritamente formal de planos e das competências dos entes federados. 
A relação convenial revela, na verdade, a imprevisibilidade das ações públicas, seu caráter emergencial, bem como sua lógica estrutural ligada a troca de favores, moedas de trocas intergovernamentais e da perpetuação da subsidiariedade ${ }^{6}$.

Neste sentido, a assistência social se coloca em um terreno de disputa que confere ao seu conteúdo um caráter contraditório de inovar conservando o cerne de uma política focalista e de caráter restritivo em relação aos direitos sociais, assim é necessário analisarmos os avanços e retrocessos na configuração do Sistema Único de Assistência Social - SUAS.

\section{O SUAS: inovações e tensões da ação estatal}

Destaca-se que embora a Assistência Social esteja contemplada no arcabouço da Seguridade Social, juntamente com a Saúde e a Previdência Social, não fica especificado a composição do sistema e os direitos concernentes a este setor.

Em relação ao conteúdo dos SUAS, apresentam-se aspectos que impõem avanços e inovações na gestão desta política social, e outras que em nossa interpretação apresentam limites no que diz respeito a configuração de um sistema republicano de gestão e garantia de direitos.

Deste quadro apreende-se que as inovações institucionais da Assistência Social, desde a PNAS (2004), trazem o desafio de concretizar o escopo da Assistência Social enquanto política e sua realização de forma pública (BRASIL, 2008). Logo, na concepção de Pereira (2007), o entendimento da assistência social enquanto política requer que esta seja encarada de forma: Racional, Ética e Cívica. Enfatizando este enfoque, Racional - vem do fato que toda política de intervenção na realidade assumida de forma pública deve pautar-se pela utilização de estudos pesquisas, diagnósticos, monitoramento e avaliação, uma vez que "[...] trata-se de um processo que implica não só gestão e aplicação de programas, serviços e recursos, mas, principalmente, definição de prioridades, estratégias

\footnotetext{
${ }^{6}$ Segundo Mestriner (2001), a subsidiariedade é um aspecto central na doutrina social da igreja que se particulariza no fato de que "o estado deve ajudar os membros do corpo social, sem contudo impedí-los de fazer o que podem realizar por si mesmos" (MESTRINER, 2001, p. 19). Neste sentido, o Estado deve subsidiar os indivíduos através das mais diversas fontes a alcançar seus fins sem precisar positivamente da ação do Estado. Os princípios da subsidiariedade são típicos de regimes de Welfare State Conservador/Corporativo explicitados por Esping-Andersen (1991), que subsidia os membros da sociedade na provisão de seu bem estar.
} 
e metas, tendo como principal compromisso a melhor satisfação possível das necessidades sociais" (PEREIRA, 2007, p. 220). Ético - Tal componente se justifica porque constitui uma responsabilidade pública que cabe indubitavelmente aos governos garantir medidas de assistência social, no sentido de ofertar a satisfação das necessidades básicas para que as pessoas possam realizar escolhas concretas sobre a vida que querem levar e sua participação social. Logo a assistência social deve eleger a justiça social como referência de sua intervenção. Cívico - O componente cívico da assistência social se afirma pela indissociável vinculação que possui com os direitos sociais, com a concretização da cidadania. Neste sentido, concretizar direitos significa assegurar as pessoas, "[...] como dever do Estado, um conjunto de benefícios e serviços que lhe é devido, em resposta as suas necessidades sociais" (PEREIRA, 2007, p. 221).

Em busca de tais sistematizações, a PNAS articula o SUAS em eixos de inovação institucional na assistência social que se caracterizam pelos seguintes conteúdos: a matricialidade sócio-familiar; territorialização; descentralização político-administrativa; co-financiamento nas três esferas de governo; relação democrática entre governo e sociedade civil; controle social; qualificação dos recursos humanos; e os sistemas de gestão, monitoramento e avaliação.

$\mathrm{Na}$ concretização de tais eixos busca-se a compreensão a articulação da rede socioassistencial. O conceito de rede socioassistencial explicitado na NOB-SUAS seria esta "um conjunto integrado de ações de iniciativa pública a da sociedade, que ofertam e operam benefícios, serviços, programas e projetos, o que supõe a articulação entre todas as unidades de provisão da proteção social" (BRASIL, 2005, p. 94). A operacionalização do serviço socioassistencial apregoado no SUAS, se concretiza através de níveis diferenciados de hierarquia e de complexidade, sendo: proteção social básica e a proteção social especial dividida em média e alta complexidade.

A ação da proteção social básica tem por objetivo prevenir situações de risco social, buscando prevenir situações e reforçar os vínculos sociais e comunitários. Este serviço se destina a população em situação de vulnerabilidade social decorrente de situações da vida em sociedade. As ações desencadeadas pela proteção social básica têm como elemento agregador fundamental o CRAS (Centro de Referência da Assistência Social), conhecido por ser a "porta de entrada" dos serviços e programas da atenção básica. A 
implantação dos CRAS leva em conta a territorialização do município, tendo em vista condições de vida, vulnerabilidade, potencialidade, que tem como referência o número de famílias referenciadas por território. A quantidade e as características operacionais do CRAS são definidas através do porte e particularidade social dos municípios ${ }^{7}$.

As ações da proteção social especial objetivam, por sua vez, atendimento às famílias e/ou indivíduos mais vulneráveis ou expostos a riscos mais graves de rompimento do vinculo social e comunitário. (LOPES, 2006, p. 88). As ações da proteção social especial se operacionalizam através dos CREAS (Centros de Referência Especializado de Assistência Social.), que objetivam dar suporte e situações em que o convívio familiar e comunitário está ameaçado ou precisa ser rompido.

Ao eleger a matricialidade sócio-familiar enquanto eixo estruturante a PNAS 2004, busca superar a focalização no individuo, garantindo a oferta de direitos sociais de acordo com as necessidades das famílias, assim como busca romper com o foco fragmentado das visões estereotipadas das famílias. Tal consideração que não passa sem críticas que serão debatidas no próximo item.

No que toca à territorialização da Assistência Social no âmbito do SUAS a Norma Operacional Básica (NOB- SUAS) entende-a enquanto movimento que busca a dinamização das potencialidades coletivas e comunitárias concebendo o território enquanto ator social. De acordo com a NOB - SUAS,

[...] trata-se de identificar os problemas concretos, as potencialidades e as soluções, a partir de recortes territoriais que identifiquem conjuntos populacionais em situações similares, e intervir através das políticas públicas, com o objetivo de alcançar resultados integrados e promover impacto positivo nas condições de vida (BRASIL, 2005, p. 44).

Atuar neste enfoque territorial pressupõe apreender as características territoriais brasileiras em sua singularidade, características cotidianas dos usuários da Assistência Social que perpassam um mosaico de situações que revelam a negação de direitos e

\footnotetext{
${ }^{7}$ A quantidade de CRAS seria estabelecida de acordo com o porte dos municípios: Pequeno I- 1 Cras para até 2500 famílias; Pequeno II- 1 Cras para até 3500 famílias referenciadas; Médio - mínimo de 2 Cras, cada um para cada 5000 famílias referenciadas; Grande- mínimo de 4 Cras, cada um para até 5000 famílias referenciadas; Metrópole- mínimo de 8 Cras, cada um para até 5000 famílias referenciadas.
} 
cidadania, dividindo a nossa sociedade em dois mundos: o mundo dos direitos e o mundo dos favores.

A descentralização político-administrativa se relaciona ao fato de que a implementação do SUAS se operacionalizará primordialmente no âmbito dos municípios, com responsabilidades e competências nas três esferas de governo, inclusive na questão do financiamento, ou seja, no co-financiamento nas três esferas governamentais. Tendo em vista estas características, os direcionamentos empreendidos pelas políticas públicas devem superar o formalismo burocrático e o pragmatismo financeiro, ou seja, a mera adequação a exigências burocráticas e visão de consecução de transferências de recursos, mas, avançando na efetivação ativa das políticas sociais em cada esfera de governo.

Outra importante inovação institucional engendrada na configuração do SUAS é a relação democrática entre governo e sociedade civil, assim como o controle social da assistência social através dos conselhos de direitos. A configuração de relações democráticas e do controle social buscam romper com a cultura do patrimonialismo e da mediação do favor, uma vez que, os critérios de partilha e distribuição de recursos são pactuados através de critérios estabelecidos na Comissão Intergestora Tripartite (CIT), que congrega representantes de gestores municipais, estaduais e federais da política de assistência social.

Neste sentido, Sposati (2006) explicita que os critérios de partilha são equacionados de forma:

A equalizar, priorizar e projetar a universalização da cobertura pela política de assistência social. Criou-se a Taxa de Vulnerabilidade Social, composta por nove indicadores. [...] essa aplicação de indicador foi reconhecida como índice SUAS, que classifica os 5563 municípios brasileiros por ordem de prioridade para o financiamento federal (SPOSATI, 2006, p. 111).

Portanto, a criação do índice Suas estabelece critérios claros de partilha entre os municípios de acordo com o porte, as condições socioeconômicas, e a alocação de recursos na política de assistência. É importante ressaltar que a prioridade se concentra nos municípios de pior situação, assim sendo, a prioridade é para os municípios de pior índice Suas. 
Uma das principais conseqüências desta nova forma de alocação e distribuição orçamentária da assistência social é a tentativa de rompimento com a visão convenial, minimalista, emergencial que sempre permeou o financiamento da política de assistência social. Outro fator importante reside no fato de que a chamada serie histórica foi substituída por pisos e níveis de atenção, garantindo maior previsibilidade as ações, além de possibilitar o planejamento objetivando a universalização do atendimento aos riscos sociais.

Na condução da assistência social, em que pese a implementação do SUAS, a configuração de uma política de recursos humanos conforma-se com fator de grande importância. Neste sentido, a aprovação da NOB/RH/SUAS busca dar sistematicidade as ações da Assistência Social e nova institucionalidade as condições de trabalho na área. Dentre os avanços a NOB/RH institui a formulação a implementação de uma política de capacitação de recursos humanos - trabalhadores, conselheiros e usuários - de forma continuada, participativa e descentralizada em âmbito nacional. Igualmente, indica a contratação por concurso público e a estruturação de condições de trabalho de acordo com as demandas exigidas pelas famílias atendidas.

Segundo conteúdo da NOB-SUAS, os instrumentos de gestão são: Plano ${ }^{8}$, Orçamento $^{9}$, e o relatório de gestão ${ }^{10}$. Ressalta-se que a operacionalização dos instrumentos de gestão explicitados na NOB-SUAS, devem contemplar o trato da qualidade dos serviços, a política de recursos humanos, os critérios de pactuação com entidades.

No que toca aos instrumentos de gestão estabelecidos pela NOB-Suas, estes não podem ser encarados de forma formalista e burocrática, mas objetivando que tais instrumentos sejam ferramentas de otimização da oferta de serviços, benefícios e programas, sob o ponto de vista da garantia de direitos sociais. Dentro destes parâmetros, torna-se fundamental a gestão da informação para a concretização democrática e republicana de uma política pública. Neste sentido, na estruturação do

\footnotetext{
8 "O Plano de Assistência Social é um instrumento de planejamento estratégico que organiza, regula e norteia a execução da PNAS/2004 na perspectiva do SUAS" (BRASIL, 2005, p.119).

9 "O financiamento da política de Assistência Social é detalhado no processo de planejamento, [...] que expressa a projeção das receitas e autoriza os limites de gastos nos projetos" (BRASIL, 2005, p. 119).

10 "O relatório de gestão destina-se a sintetizar e divulgar informações sobre os resultados obtidos e sobre a probidade dos gestores do Suas às instâncias formais do Suas, ao Poder Legislativo, ao Ministério Público e à sociedade como um todo" (BRASIL, 2005, p. 121).
} 
SUAS, incorporou-se a gestão da informação sobre a política de assistência denominado Rede SUAS.

De acordo com Tapajós (2006), "a Rede suas foi projetada, e está sendo desenvolvida, para o suporte à gestão, financiamento e controle social, o monitoramento e avaliação de programas, serviços, projetos e benefícios, alcançando integralmente essa política pública". (TAPAJÓS, 2006, p. 188) Com o advento da estruturação da rede SUAS, incorporou-se a noção de maior racionalidade e rapidez aos processos de monitoramento e avaliação das ações da política pública de assistência, corroborando ao maior espaço destinado ao planejamento e a avaliação através do acúmulo de dados armazenados, que podem propiciar uma maior nitidez ao âmbito da efetivação da política de assistência social.

Segundo Tapajós (2006), a Rede SUAS é composta por vários ambientes que se destinam a diferentes usuários, desde a população em geral, até os gestores da assistência social em qualquer escala de governo. Não obstante, o trato qualificado da gestão da informação é imperativo na gestão democrática das políticas sociais, seu controle social, bem como é uma ferramenta eficaz para a transparência e visibilidade pública das ações no campo da assistência social.

Assim sendo, são centrais as ponderações discorridas por Sposati (2006) quanto aos desafios à efetivação da política de assistência social enquanto extensão das medidas de proteção social da seguridade social brasileira. Deste modo, o ingresso da assistência social como política pública exige que esta deva:

a) Ser planejada - o que exige o conhecimento prévio da realidade através da função da vigilância social, conhecendo demandas e necessidades, construindo metas.

b) Ser orçamentada - o que supõe o desenvolvimento da tecnologia de orçamentação da assistência social, o que é muito mais do que definir percentuais de gastos anuais.

c) Dispor de um quadro de trabalhadores permanentes e capacitados para o exercício de suas funções.

d) Desenvolver tecnologias de gestão, conhecimentos teóricos e metodologias do trabalho social.

e) Fortalecer mecanismos de gestão democrática

f) Ser avaliada - o que indica a necessidade da discussão dos resultados e de seus indicadores o que é muito mais do que estabelecer o número e atendimentos (SPOSATI, 2006, p. 115). 
Desse modo, é necessário que todas as instâncias do pacto federativo brasileiro realizem a mudança no entendimento do caráter da política de assistência social, encarada de forma republicana, afiançando direitos sociais com vistas à universalidade.

Acrescenta-se a necessidade de se romper com os estigmas e representações que perpassam a dinâmica da política de assistência social, rompendo com o patrimonialismo, clientelismo e com relações de favor, tantas vezes personificadas nas figuras das primeiras damas, isto é um desafio a ser alcançado em todas as esferas, mas sobremaneira nos municípios do universo pesquisado.

De acordo com Behring (2008), bem como em relação as discussões anteriromente feitas, as principais possibilidades de inovação pressupostas no SUAS, são: constituição de uma rede de serviços socioassistenciais de forma territorial, fortalecimento dos instrumentos de gestão. Ou seja, a inovação se configura na instalação de uma maior capacidade operacional da política social de assistência

A instalação de uma maior capacidade operacional se torna fato preponderante, sobretudo, em um contexto histórico de precarização e residualidade desta política. Não obstante, a capacidade de gestão se afigura "[...] importante numa área marcada pela superposição de recursos, pelo favor, e é fundamental para a vida dos cidadãos que acessarem os benefícios e serviços [...]" (BEHRING, 2008, p. 167).

As tensões da ação estatal na configuração do SUAS perpassam os entendimentos na visão dos autores que neste tópico serão explicitados, aspectos que podem acarretar dimensões conservadoras na política de assistência social no Brasil.

O primeiro dos aspectos destacados como dimensões conservadoras da assistência social no Brasil elencado na PNAS é o eixo da Matricialidade sócio-familiar. Embora a PNAS destaque o entendimento de família de forma plural que comporta diferentes arranjos, o limiar da inovação ao conservadorismo se torna bastante tênue, pois não basta demarcar as transformações que perpassam as famílias, "se persistirem abordagens conservadoras e disciplinadoras no trabalho profissional que se realiza" (BRASIL, 2008, p. 59).

Desde a crise mundial do capitalismo ocorrida na década de 1970, a família vem sendo redescoberta enquanto fonte privada de bem-estar. Em decorrência disto, tornouse parte da estratégia de quase todas as agências governamentais e não-governamentais, 
realizar medidas de intervenção junto às famílias. Concomitantemente à sua redescoberta enquanto ente de proteção social, a família emerge enquanto categoria acadêmico-científica importante, sobretudo, em relação à ação estatal, ou seja, em relação ao campo das políticas públicas (PEREIRA, 2006b).

Ou seja, para Pereira (2006b) as causas da pobreza para este enfoque de políticas sociais acima explicitados, não estão relacionadas à "questão social", e ainda fazem uma leitura da pobreza a partir da incapacidade e fracasso pessoal de prover seu autosustento e bem-estar. Nessa mesma direção, as políticas de família na maioria das vezes apresentam uma desconexão com a realidade familiar, apresentando visões idílicas sobre famílias.

Este enfoque põe em jogo não só a questão da eficácia da intervenção estatal ou da sociedade em termos das vantagens comparativas, mas se afirma por ser

[...] uma estratégia de esvaziamento da política social como direito de cidadania, já que, com o 'desvanecimento das fronteiras entre esfera pública e privada' se alarga a possibilidade de privatização das responsabilidades públicas, com a conseqüente quebra da garantia de direitos (PEREIRA, 2006b, p. 33).

Deste modo, a centralidade da família no âmbito do SUAS deve ser abordada e sistematizada com o maior cuidado, para que esta não seja enfatizada de forma regressiva gerando uma responsabilização e pressão sobretudo em relação às famílias pobres. De tal forma, a matricialidade sócio-familiar no âmbito do SUAS corre o risco de se tornar um "avanço em direção ao passado", abordando como forma progressista quesitos presentes na nas formas tradicionais de proteção social. (Laurrell, 2004).

Outro foco de tensão presente configuração do SUAS é o item da descentralização político-administrativa, uma vez que esta não apresenta um valor inequívoco independente dos atores que o advogam. Tanto setores da direita quanto da esquerda sustentam as estratégias de descentralização enquanto medidas de inovação institucional, porém, por vieses diferenciados. A defesa neoliberal da descentralização perpassa a estratégia privatizante e a superação da "tutela" do Estado frente aos entes econômicos. Na direção oposta aponta a estratégia de descentralização dos setores 
progressistas da esquerda, que vislumbram este processo enquanto estratégia para a aproximação e redefinição das relações entre Estado e sociedade.

Deste modo, Stein (1997) destaca duas concepções fundamentais sobre a abordagem do termo descentralização. Primeiramente estaria colocada a concepção neoliberal, que relaciona a descentralização com a redução do gasto público e à privatização dos serviços sociais. Neste aspecto a descentralização não se direciona à universalização dos direitos sociais. Não obstante, tal direção da descentralização objetiva desresponsabilizar os governos centrais e redirecionar as responsabilidades aos governos locais, sem, no entanto, operar a necessária divisão de capacidades institucionais e orçamentárias.

$\mathrm{Na}$ perspectiva inversa às teses liberais, as estratégias de descentralização se organizam buscando operar a descentralização enquanto redefinição das relações entre os diferentes níveis de governo, e destes com a sociedade. Tais medidas seriam organizadas em direção a uma relação mais democrática. No que diz respeito à articulação entre descentralização e democracia, esta articulação seria entendida como "intermediação das divergências sociais enquanto um instrumento de expansão da lógica democrática, à medida que amplia as instâncias de negociação e, consequentemente, de conciliação" (STEIN, 1997, p. 83).

Diante deste debate, dependo do modo como se articulam as forças sociais locais, bem como os diferentes contextos institucionais, podemos visualizar as estratégias de descentralização se tornando medidas de desresponsabilização do poder público, sem, no entanto, efetivar uma gestão pública democrática. Portanto, na visão dos críticos ao processo de descentralização tais medidas estariam reforçando ao invés de mudar relações socais verticais existentes nos municípios, sobretudo, nos municípios de pequeno porte.

Em síntese, os críticos em relação ao processo de construção do SUAS advogam que os parâmetros estabelecidos pela PNAS e pela NOB operam o reforço de medidas que não deixam claras as ações estatais, bem como seu conteúdo reforçaria medidas conservadoras de retorno a família e aos entes de sociabilidade primária em detrimento de garantias de direito e garantias sociais exigíveis. 
É importante destacar que o direcionamento de conformação do SUAS se da na arena de disputas políticas, que em certa medida carregam o legado histórico dos direitos sociais no Brasil, pois, velhas políticas influenciam novas políticas, o que conforma no Brasil uma travessia entre a originalidade e o conservadorismo.

\section{Considerações finais}

Diante das considerações expostas no decorrer do artigo apresentam-se algumas considerações a se fazer em relação às inovações e tensões da ação estatal no que diz respeito ao SUAS. Ou seja, procurou-se demarcar os avanços da política e os pontos contraditórios da mesma.

No que toca aos aspectos positivos visualiza-se a demarcação de uma maior capacidade de gestão a sistematização da assistência social através dos instrumentos de gestão monitoramento e avaliação e a gestão territorial das políticas sociais. Estes instrumentos de gestão e sua operacionalização dinamizaram o desenho institucional da política pública, em que se nota que tem demonstrado um bom desempenho, representado pelo grau de habilitação ao SUAS pelos municípios, seja pelo estabelecimento de repasses regulares de recursos, ou mesmo pelo sistema de sanções e recompensas em relação aos diferentes níveis de habilitação.

Nota-se por conseqüência, diante do debate desenvolvido neste artigo que o SUAS busca consolidar a responsabilidade estatal no âmbito da assistência social. Porém, não está claro se essas inovações são sustentáveis ao longo prazo sem o apoio financeiro e a indução do governo federal. Assim sendo, a implementação do SUAS pressupõe uma redefinição das relações no pacto federativo com reforço do desenho institucional da PNAS, sobretudo no que diz respeito a responsabilidades e atribuições dos municípios. Ressalta-se que além da descentralização de atribuições e responsabilidades deve ocorrer também a descentralização da capacidade técnica e orçamentária para que realmente os municípios possam em sua particularidade empreender a política de Assistência Social ampliando sua capacidade estatal.

Porém, este avanço gera importantes tensões com uma política econômica de altos superávits primários, através de retirada de recursos da seguridade social para 
pagamento de juros da divida externa, fato que se contrapõe à estruturação de serviços, ampliação das estruturas estatais e da universalização da assistência social no Brasil.

No campo destas tensões há que se atentar para o risco de supervalorização do escopo da assistência social configurando à mesma a responsabilidade de realizar isoladamente a proteção social, o que se configura na visão de Motta entre outros (2007) na assistencialização da seguridade social. Tal dinâmica se expressa, por exemplo, na defasagem existente entre o número de benefícios pagos diretamente e a oferta de serviços no âmbito da assistência social, seja do ponto de vista quantitativo ou qualitativo.

Outro fator de tensão é a defesa da família como ente central da oferta de bemestar descontextualizando as diversas transformações da mesma e os processos sociais mais gerais da sociedade dividida em classes. A responsabilização das famílias em relação à proteção social corre o risco de ocultar as contradições sociais, entendendo a família como via de superação da questão social, através de trabalhos sociais que visam alterar comportamentos e atitudes considerados "desviantes". Estas ações acarretam em uma culpabilização das famílias e aumento das pressões em relação às expectativas das tarefas que estas famílias devem cumprir, sobretudo as mais pobres.

Em síntese, temos que avançar no sentido da qualificação e do conteúdo dos serviços públicos no sentido de um sistema efetivo e eficaz e universal, no sentido do entendimento de que O SUAS não é apenas um instrumento gerencial, mas, sobretudo um instrumento político, que expressa um campo de lutas e contradições inerentes à política de Assistência Social em nosso país, que busca se assentar na concretização e ampliação da proteção social não contributiva no campo socioassistencial, e só se efetivará com a inequívoca responsabilidade e capacidade estatal na provisão e condução desta política.

\section{Referências}

ALAYON, N. Assistência e assistencialismo: controle dos pobres ou erradicação da pobreza? São Paulo: Cortez, 1995. 
BEHRING, E. R. Trabalho e seguridade social: o neoconservadorismo nas políticas sociais. In: BEHRING, E.; ALMEIDA, M. H. T. Trabalho e seguridade: percursos e dilemas. São Paulo: Cortez, 2008. p. 152-174.

BERETTA, R. C. de S.; MARTINS, L. C. de O. Estado, municipalização e gestão municipal. Revista Serviço Social e Sociedade, São Paulo, n. 77, p. 63-77, mar. 2004.

BORÓN, A. A. A sociedade civil depois do dilúvio neoliberal. In: SADER, e.; GENTILI, P. (Org.). Pós-meoliberalismo: as políticas sociais e o estado democratic. Rio de Janeiro: Paz e Terra, 1995.

BRASIL. Ministério do Desenvolvimento Social e Combate a Fome. Norma Operacional Básica NOB/SUAS. Brasília, 2005.

Secretaria Nacional de Assistência Social. SUAS: configurando os eixos de mudança. Brasília: MDS, 2008. Caderno 1.

CARDOSO JUNIOR, J. C.; JACCOUD, L. Políticas sociais no Brasil: organização, abrangência e tensões da ação estatal. In: JACCOUD, L. (Org.). Questão social e políticas sociais no brasil contemporâneo. Brasília: IPEA, 2005. p. 181-260

CARVALHO, R.; IAMAMOTO, M. V. Relações sociais e serviço social no Brasil. São Paulo: Cortez, 1985.

CASTEL, R. As metamorfoses da questão social: uma crônica do salário. Petrópolis: Vozes, 1998.

COHN, A.; DRAIBE, S.; KARSCH, Ú. Desafios atuais para a assistência social: a busca de alternativas. São Paulo: FUNDAP, 1995. Mimeo.

DRAIBE, S. Brasil: o sistema de proteção social e suas transformações recentes. Santiago do Chile: Cepal, 1993. (Série Reformas de Políticas Públicas, n. 14).

ESPING-ANDERSEN, G. As três economias políticas do Welfare state. Lua Nova, Rio de Janeiro, n. 24, 1991.

FONSECA, A. M. Família e política de renda mínima. São Paulo: Cortez, 2001.

INSTITUTO DE PESQUISA ECONÔMICA APLICADA - IPEA. PNAD 2006: primeiras análises. Brasília: IPEA, 2006.

LOPES, M. H. C. O tempo do SUAS. Revista Serviço Social e Sociedade, São Paulo, n. especial, p. 76-95, 2006.

MESTRINER, M. L. O estado entre a filantropia e assistência social. São Paulo: Cortez, 2001.

PEREIRA, P. A. A política social no contexto da seguridade social e do Welfare State: a particularidade da Assistência Social. Serviço Social e Sociedade, São Paulo, n. 56, 1998. 
. Mudanças estruturais, política social e papel da família: crítica ao pluralismo de bem-estar. In: SALES, M. A.; MATOS, M. C.; LEAL, M. C. (Org.). Política social, família e juventude: uma questão de direitos. 2. ed. São Paulo: Cortez, 2006b. p. 25-42.

. Necessidades humanas: subsídios a critica dos mínimos sociais. São Paulo:

Cortez, 2006a.

O primeiro ano do Sistema Único de Assistência Social. Revista Serviço Social e Sociedade, São Paulo, n. esp., p. 96-122, 2006.

. Sobre a política de assistência social no Brasil In: PEREIRA, P. A.; BRAVO, M. I. S. (Org.). Política social e democracia. 3. ed. São Paulo: Cortez, 2007. p. 110-236

RAICHELIS, R. Esfera pública e conselhos de assistência social: caminhos de construção democrática. São Paulo: Cortez, 2000.

SANTOS, W. G. Cidadania e justiça social. Rio de Janeiro: Campus, 1979.

SOUZA, M. de F. Implementação municipal do SUAS - Sistema Único da Assistência Social: balanço das condições de gestão da assistência social em municípios do Vale do Paraíba. São Paulo. 2006. Dissertação (Mestrado em Serviço Social) - Pontifícia Universidade Católica de São Paulo, São Paulo, 2006.

SPOSATI, A. Desafios para fazer avançar a política de assistência social no Brasil. Revista Serviço Social e Sociedade, São Paulo, n. 68,. p. 54-82, 2001.

SPOSATI, A.; FALCÃO, M; do C.; TEIXEIRA, S. M. F. Os direitos (dos desassistidos) sociais. São Paulo: Cortez, 1995.

STEIN, R. H. A descentralização como instrumento de ação política e suas controvérsias. Serviço Social e Sociedade, São Paulo, n. 54, p.75-94, 1997.

TAPAJÓS, L. Gestão da Informação no SUAS. Revista Serviço Social e Sociedade, São Paulo, n. esp., p.178-201, 2006.

YAZBEK, M. C. Terceiro setor e despolitização. Revista Inscrita, BRASILIA, jul. 2000.

Recebido em: 12/02/2011

Aprovado em: 15/04/2011 